\title{
Ritalin Dose Response Effect on Medial Prefrontal Cortex and on Animal Behavior
}

\author{
Cruz Reyes-Vasquez, Corey J. Cannon, Nachum Dafny* \\ Department of Neurobiology and Anatomy, The University of Texas Health Science Center McGovern Medical \\ School, Houston, Texas, USA \\ Email: *Nachum.dafny@uth.tmc.edu
}

Received 18 February 2016; accepted 25 March 2016; published 28 March 2016

Copyright (C) 2016 by authors and Scientific Research Publishing Inc.

This work is licensed under the Creative Commons Attribution International License (CC BY). http://creativecommons.org/licenses/by/4.0/

c) (i) Open Access

\section{Abstract}

The prefrontal cortex (PFC) is involved in complex planning, learning, memory, attention and integrates sensory information. It was reported that the PFC was dysfunctional in attention deficit hyperactivity disorder (ADHD). Methylphenidate (MPD), a drug often prescribed for the treatment of ADHD, has potential for abuse and misuse. Most MPD studies were completed in adult subjects; however, most users were adolescents. The objective of this study was to investigate the acute and chronic dose response characteristics of MPD on PFC neuronal activity recorded in freely behaving adolescent rats. Four groups of animals were used: saline (control), 0.6, 2.5, and $10 \mathrm{mg} / \mathrm{kg} \mathrm{MPD}$. Acute MPD elicited a dose response increase in animals' locomotor activity. Rechallenge with MPD at experimental day (ED10) when compared to the effect of MPD at ED1 showed no significant differences. When the animals were divided into two groups based on their individual responses to chronic MPD exposure, some animals expressed behavioral tolerance and some expressed behavioral sensitization. Electrophysiologically, a dose response characteristic for acute and chronic MPD exposure was observed. With increasing MPD doses, more PFC units responded by changing their firing rate. Moreover, the neuronal responses to chronic MPD recorded from animals expressing behavioral tolerance were significantly different compared to the neuronal population responses recorded from animals expressing behavioral sensitization. The majority of the PFC units recorded from animals expressing behavioral tolerance responded to MPD predominately by decreasing their firing rates, whereas PFC units recorded from behaviorally sensitized animals mainly showed an increase in their firing rates.

\section{Keywords}

Adolescent, Prefrontal Cortex (PFC), Ritalin, Behavior, Neuronal, Acute, Chronic Psychostimulant

\footnotetext{
*Corresponding author.
} 


\section{Introduction}

The PFC is involved in those characteristics that distinguish humans from other animals, such as self-awareness, the capacity for complex planning, problem solving, learning and memory. The PFC uses working memory to guide behavior and attention. It has interconnections with different cortical diencephalic and brain stem structures. The PFC integrates sensory information from both the outside world and the body. The PFC is reported to have an important role in cognitive performance and attention [1]-[4]. MPD is used to treat ADHD patients as a cognitive enhancer [5] [6]. MPD exerts its effects on the DA system, and the PFC is comprised of largely DA receptors [7] [8]. Thus, for this study, the PFC was chosen as the area of interest because of its importance in cognition processes, working memory, and attention [1]-[4]. Attention-deficit hyperactivity disorder (ADHD) is one of the most common behavioral problems in children, with studies from the globe around citing a prevalence rate anywhere from $1.7 \%$ to as high as $16 \%$ depending on regional methods of diagnosis [9]-[12]. Methylphenidate (MPD), a psychostimulant synthesized over fifty years ago, has become the drug of choice for treating ADHD in more than 90\% of patients in the United States [2] [12]. From 1990 to 1995 alone, there was a 2.5-fold increase in MPD usage in children [12] [13]. And it is estimated that $8.7 \%$ of US children meet the criteria for ADHD diagnosis [14].

With such a high rate of prescription and potential misuse and abuse of MPD by adolescents and young adults [15], it is essential to study how acute and chronic MPD treatment can affect these age groups in animal models. The developing brain undergoes profound rearrangement of its morphology and function, including changes in synaptic and receptor density [16], as well as changes in the density of dopamine (DA), norepinephrine (NE), and 5-HT transporters during adolescence [17] [18]. The neuronal response to MPD in the young individual is likely to be different from the adult response, particularly in the prefrontal cortex (PFC), a brain structure that does not fully develop until adulthood [18]-[20]. Thus, it is reasonable to assume that drug efficacy will be different in children and adolescents, compared to adults.

MPD and cocaine both have the ability to bind to DA transporters (DAT) and thus preventing the reuptake of dopamine from the synaptic cleft back to the presynaptic terminals; thus prolonging the action of DA in the synaptic cleft [21]. There are several studies that report the differentiated effects of MPD on adolescent compared to adult brains [19] [22]-[27]. For example, DAT density in the striatum of rats that were treated with MPD in childhood and adolescence was lower than in rats which began treatment as young adults [26]. MPD has been shown to produce an age and dose dependent increase in extracellular DA and NE levels [24]. In adolescent rats treated with MPD, the extracellular DA levels were higher than those in treated adults [27]. Basal firing rate and bursting activity of DA ventral tegmental area (VTA) neuronal activity in adolescents also differed from those recorded in adult rats [22]. Experiments using FMRI have shown drastically different responses to MPD exposure between adult and adolescent rats in the PFC, nucleus accumbens, and hippocampus [23]. In previous experiments using adult animals, the same chronic MPD dose of $0.6,2.5$, and $10 \mathrm{mg} / \mathrm{kg}$ in some animals elicited behavioral sensitization and in others elicited behavioral tolerance [28]-[31]. We hypothesize that: 1) the same acute MPD dose will elicit behavioral sensitization in some adolescent animals and behavioral tolerance in other adolescent animals and 2) PFC units recorded following chronic MPD exposure in animals expressing behavioral tolerance will respond differently from PFC units recorded from animals expressing behavioral sensitization. Therefore, the objective of this experiment is to study the acute and chronic dose response characteristics of MPD on PFC neuronal activity simultaneously with animal behavior in adolescent rats and to evaluate the neuronal activity data based on animal behavioral responses. PFC units recorded from animals expressing behavioral sensitization to repetitive (chronic) MPD exposure were evaluated separately from the PFC neuronal activity recorded from animals that did not express behavioral sensitization (i.e. tolerance).

\section{Materials and Methods}

\subsection{Subjects}

One hundred and thirty adolescent male Sprague-Dawley rats at a post-natal age of 30 - 32 days, weighing 50 $60 \mathrm{~g}$ were purchased from Harlan Laboratories (Indianapolis, IN, USA). They were individually housed in single Plexiglass cages that served as both their home and test cage, with an ambient room temperature of $21^{\circ} \mathrm{C} \pm$ $2^{\circ} \mathrm{C}$ and a relative humidity of $58 \%-62 \%$, and allowed to acclimate for $3-5$ days prior to electrode implantation. The room was lit on a 12:12 hour light/dark schedule, beginning with the light on at 06:00 am. Food and water was provided to the rats ad libitum. The concomitant behavioral and neuronal recording began on post- 
natal day 40 (P-40) and lasted for 10 days until P-50; this age range has been determined to correlate with human adolescence by several investigators [32]-[36]. All experiments conducted were approved by the institutional Animal Welfare Committee and complied with NIH guidelines.

\subsection{Electrode Implantation}

Animals were anesthetized with $30 \mathrm{mg} / \mathrm{kg}$ i.p. pentobarbital, the head was shaved, and then the animal was placed into a stereotaxic instrument. The skin, connective tissue, and muscle was retracted from the skull, and bilateral holes were drilled into the skull above the prefrontal cortex (PFC) $9.0 \mathrm{~mm}$ anterior to the lambda and $0.6 \mathrm{~mm}$ lateral to the midline [37]. The electrodes were two twisted $60 \mu$ in diameter, Nickel-Chromium diamel wire teflon-coated except for the tips $(80 \mathrm{~m} \Omega$ each). Each of the twisted electrodes (i.e., total 4 recording electrodes) was inserted $2.8 \mathrm{~mm}$ below the skull, aiming for PFC, also known as region 3 or the cingulate cortex [37]. While the electrodes were being inserted, neuronal unit activity was monitored using a Grass P-511 amplifier and its cathode follower. If no adequate spikes were found at the initial location of the electrode, the electrode was moved down in 5 micron increments until at least a 3:1 signal to noise ratio spikes was obtained. Once a position with favorable neuronal activity was found, the electrode was fixed in place with dental cement. The second twisted electrode was implanted similarly [38]-[42]. The four electrode leads with their pins were then inserted into an amphenol plug, and the plug was anchored onto the skull with dental cement. The rats were then allowed to recover for 4 - 6 days and were placed into the electrophysiological and the behavioral experimental system for 2 hours adaptation each day while in their homecage. A Triangle Biosystems Inc. (TBI) Durham, NC head stage transmitter (weight less than $5 \mathrm{~g}$ ) was connected to the head plug to allow acclimation to the experimental environment and the equipment used.

\subsection{Drug}

Methylphenidate hydrochloride (MPD) was donated by Mallinckrodt Inc. (St. Louis, MO, USA). MPD was dissolved in a $0.9 \%$ isotonic saline solution, and dosages were calculated as free base. The MPD dosages of 0.6, 2.5 , and $10 \mathrm{mg} / \mathrm{kg}$ were chosen based on experimental dose responses from prior studies in which these MPD doses produced behavioral sensitization and/or tolerance [43]-[50]. All injections, including the control group, were equalized to $0.8 \mathrm{cc}$ using $0.9 \%$ saline so that all animals would receive intraperitoneal (i.p.) injections of equal volume.

\subsection{Experimental Protocol}

The rats were randomly assigned to one of the following four groups: saline (control) or $0.6,2.5$, or $10 \mathrm{mg} / \mathrm{kg}$ MPD. The experiment spanned for 10 consecutive days, and all the recordings, both behavioral and electrophysiological, were done simultaneously in the animal's home cage. The home cage was used as the testing cage to eliminate the environment contribution of the drug effects, such as novel conditions. This arrangement allowed the interpretation that any change from baseline activity was related to the MPD effect [51]. On the morning of experimental day one (ED1), before the first recording session, the rats were acclimated again to the system for about 30 minutes. During these 30 minutes, the electrophysiological activity was monitored and used to set the recording software parameters to capture the electrical activity and prepare the injection solutions of both the saline and the MPD. The rats then received a $0.8 \mathrm{cc}$ saline injection immediately followed by a 60 minute recording session to gather baseline neuronal and behavioral activity. The rats were then injected with either saline (i.e. the control group) or MPD according to their dosage group, and recording was resumed for an additional 60 minutes (Table 1). From ED2 - ED6, the rats were injected daily with the amount of saline or MPD as previously assigned on ED1 in their home cage. ED7 - ED9 was a washout period, during which no injections were given to the rats. On ED10, the same procedure as on ED1 was completed again, with saline injections to record neuronal and behavior baseline activity for an hour followed by either saline or MPD injections and recordings for an additional hour post injection (Table 1). This experimental design was based on our prior studies [7] [8] [29]-[31] [39] [42] [43] [45] [48]-[50].

\subsection{Behavioral Apparatus}

A computerized animal activity system (Accuscan Instruments Inc., Columbus, OH) was used to gather the 
Table 1. Experimental protocol.

\begin{tabular}{|c|c|c|c|c|}
\hline Experimental Day & 1 & $2-6$ & $7-9$ & 10 \\
\hline \multicolumn{5}{|l|}{ Treatment Group } \\
\hline Saline $(\mathrm{N}=14)$ & saline/saline & saline & washout & saline/saline \\
\hline $0.6 \mathrm{mg} / \mathrm{kg}(\mathrm{N}=36)$ & saline $/ 0.6 \mathrm{mg} / \mathrm{kg}$ & $0.6 \mathrm{mg} / \mathrm{kg}$ & washout & saline $/ 0.6 \mathrm{mg} / \mathrm{kg}$ \\
\hline $2.5 \mathrm{mg} / \mathrm{kg}(\mathrm{N}=39)$ & saline $/ 2.5 \mathrm{mg} / \mathrm{kg}$ & $2.5 \mathrm{mg} / \mathrm{kg}$ & washout & saline $/ 2.5 \mathrm{mg} / \mathrm{kg}$ \\
\hline $10.0 \mathrm{mg} / \mathrm{kg}(\mathrm{N}=41)$ & saline $/ 10.0 \mathrm{mg} / \mathrm{kg}$ & $10.0 \mathrm{mg} / \mathrm{kg}$ & washout & saline $/ 10.0 \mathrm{mg} / \mathrm{kg}$ \\
\hline
\end{tabular}

locomotor behavioral data. The clear acrylic home cages $(40.5 \times 40.5 \times 31.5 \mathrm{~cm})$ of the animals fit into the behavioral system and therefore allowed recording to take place within the home cage of the rat. The open field system consists of two parallel arrays of 16 infrared beams with sensors $2.5 \mathrm{~cm}$ apart located $5 \mathrm{~cm}$ above the cage floor. Every $100 \mathrm{~Hz}$, the program checked for beam interruption. Beam interruptions over each 10 minute period were summed to one bin by the OASIS data collection software. The OASIS program organized the beam interruptions into several different locomotor movement indices: horizontal activity (HA) which recorded the overall locomotor activity, and number of stereotypic movements (NOS) which counts the number of repetitive episodes with at least a one second interval [45]. Counts were compiled every 10 minutes during the 60 minute recording sessions described above after saline injection and following drug exposure for ED1 and ED10 and downloaded to a PC. The behavioral data was evaluated first to determine which individual animals exhibited behavioral sensitization or tolerance, and the electrophysiological unit data was statistically evaluated based on these behavioral results.

\subsection{Behavioral Data Analysis}

Six bins of data resulting from each sixty minute recording session were used to analyze the data for each animal. Three comparisons were made with this data. The first comparison was the recordings obtained at ED1 post initial MPD exposure vs the recordings collected after saline baseline injections to determine the acute effect of the treatment. The second comparison involved the baseline activity of ED10 vs baseline activity recorded at ED1 to examine whether the repetitive (chronic) six saline or MPD daily injections and three washout days modulated the baseline activity at ED10. The third comparison analyzed activity following the rechallenge of MPD at ED10 vs the MPD given at ED1 (Table 1) to determine if sensitization or tolerance had occurred over the course of the experiment. The critical ratio (C.R.) test was used to determine the effect of the treatment in animals' behaviors C.R. $=(E-C) / \sqrt{(E+C)} \pm 1.96=P<0.05,(C=$ control activity, $E=$ treatment activity) [7] [8] [29] [30] [39] [40]. Behavioral sensitization is defined as a significant acceleration of locomotor activity following repetitive (chronic) drug exposure at ED10 when compared to the initial MPD exposure at ED1. Behavioral tolerance is defined as the chronic effect of the drug having no significant effect or significantly less effect on the locomotor activity as compared to the initial effects. These rats were summed into two "subgroups" and each was analyzed again as a subgroup using a two way analysis of variance (ANOVA: treatment days and drug doses). Any statistical significance was determined with the Turkey LSD methods. Statistical significance was set at $\mathrm{P}<0.05$ for all comparisons.

\subsection{Electrophysiological Data}

\subsubsection{Data Acquisition}

The home cage with the rat was placed into a Faraday testing box to lessen noise during the recording. The TBI head stage was connected to the rat head cup containing the electrode pins that sent the electrical signals at sampling rates up to $200 \mathrm{kHz}$ through a transmitter to a receiver that connected to a Cambridge Electronic Design (CED) analog-to-digital converter (Micro1401-3) that digitized the data and transferred them to a PC to be stored. Spike 2.7 CED software was then used off-line to inspect and to sort for individual spikes based on their amplitudes and waveforms.

\subsubsection{Spike Sorting}

Spike 2.7 software fixed template matching system (FTMS; Cambridge Electronics Design-CED) was used of- 
fline for spike sorting. The program algorithm captured the raw recording using low and high pass filters $(0.3-3$ $\mathrm{kHz}$ ) to process them, as well as two window discriminator levels set for positive-going spikes and for negative-going spikes. Those spikes with amplitudes outside the window discriminators were discarded. The selected captured PFC spike was defined by using 1000 waveform data points, and templates were created from this selected spike. The Spike 2.7 software algorithm for capturing a spike allowed for the extraction of templates to be used for sorting the selected spike amplitude and pattern despite noise influences, false threshold crossing, and waveform overlap. All time-displaced templates are compared with the selected spike event to find the template that best results in the minimum residue variance. Then a template-matching procedure occurs, and when the distance between the template and waveform is over a threshold of $80 \%$, the waveforms are rejected. Therefore spike sorting accuracy is about $95 \%$ for the reconstructed data. The criteria to sort spikes in ED1 and ED10 from a particular electrode of the same animal was identical, however, it is impossible to guarantee that the recording is from the same unit.

\subsection{Electrophysiological Data Analysis}

After the fixed template matching system sorted the neuronal activity, the Spike 2.7 software (CED) summed the accepted total number of spike and calculated the sorted spikes' firing rates (spikes/sec) for both the baseline recording and for the activity post-MPD administration at ED1 and ED10. The firing rates were then put on a spread sheet with information regarding the rat's number, experimental day, dosage of MPD given, and channel (to distinguish between the electrodes) and a temporal firing rate graph was produced. The sum of each 60 minute segment firing rate was used to calculate the effect of the treatment and the same three comparisons listed in the behavioral data analysis were used. Several methods were used to determine whether the MPD elicited significant effects on PFC neuronal activity as follows: the mean activity after treatment needed to be at least two standard errors (S.E.) different from the control mean firing rate. Firing rates were evaluated also for normality assumptions to determine parametric or nonparametric methods. To evaluate differences between the above comparisons, the firing rates were determined not to hold normality assumptions so the treatment effect on firing rates were assessed using the critical ratio (C.R.) test.

C.R. $=(\mathrm{E}-\mathrm{C}) / \sqrt{(\mathrm{E}+\mathrm{C})} \pm 1.96=\mathrm{P}<0.05 \quad(\mathrm{C}=$ control, $\mathrm{E}=$ activity after treatment $)$. C.R. test values more than 1.96 indicated that the treatment elicited significant increase in activity, while C.R. values more than -1.96 indicated that the treatment elicited significant attenuation in the neuronal activity [7] [8] [29]-[31] [38] [39] [41]. In the first comparison using the C.R. equation, the ED1 baseline activity was the control (C) and the initial (acute) response (R) following MPD exposure was R. In the second comparison, the ED1 baseline was $\mathrm{C}$ and the ED10 baseline R. In the third comparison, the initial response to MPD of ED1 was C and the data following MPD rechallenge at ED10 was $\mathrm{R}$ in the equation. In addition a log linear model using a likelihood ratio statistic $\left(\mathrm{x}^{2}\right)$ (with chi-square distribution) was used to determine if there was a statistically significant difference between the neuronal populations recorded from either 0.6 , or 2.5 , or $10.0 \mathrm{mg} / \mathrm{kg}$ MPD doses for animals expressing behavioral sensitization compared to the same dose for the animals exhibiting behavioral tolerance. P-values of $<0.05$ obtained from the log linear model were considered significant.

\subsection{Histological Verification of Electrode Placement}

After the recording was concluded on ED10, rats were anesthetized with an overdose of sodium pentobarbital, and the animals were transcardially perfused with $10 \%$ formalin solution containing $3 \%$ potassium ferrocyanide. A $2 \mathrm{~mA}$ DC current was passed through the electrode pin for 20 seconds to form a lesion. The brain was then removed and stored in $10 \%$ formalin solution. Electrode placement was verified in cresylviolet stained coronal sections that were 60 microns thick. Using the Sherwood and Timiras, A Stereotaxic Atlas of the Developing Rat Brain (1970), the position of the electrode tips was mapped out by matching the locations of the lesion and prussian blue spot (Figure 1). Only recordings from animals that had their electrodes verified to be in the PFC and exhibited the same spike amplitude and pattern at ED1 and ED10 were included in the study.

\section{Results}

\subsection{Behavioral Data}

One hundred and thirty animals were used. $14,36,39$ and 41 were treated with saline, $0.6,2.5$, and $10.0 \mathrm{mg} / \mathrm{kg}$ 


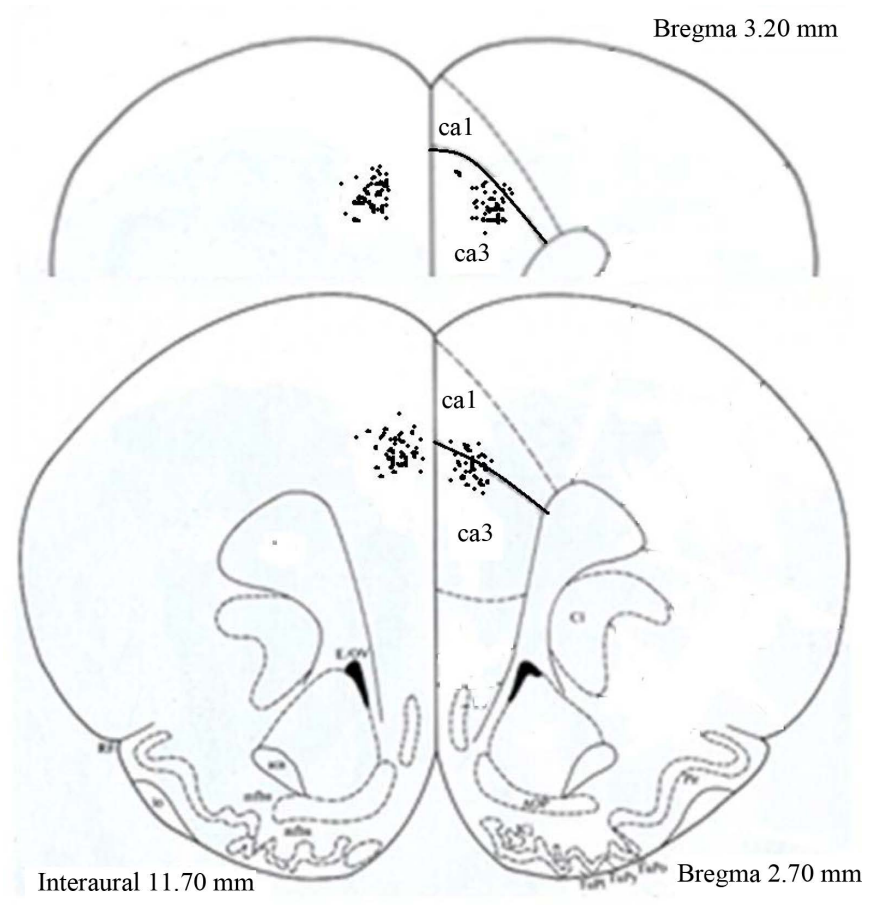

Figure 1. Histological reconstruction of the electrode tip placement in the PFC. The black dots represent the electrode tips.

MPD respectively. The locomotor activity following the 2nd saline injection on experimental day 1 (ED1) compared to the locomotor activity after the 1 st saline injection $(\mathrm{N}=14$ animals) produced minute non-significant fluctuation between the recording session. The activity at ED10 after each saline injection was similar to the activity after saline injection at ED1. Similar observations recorded for 42 days $(\mathrm{N}=8)$ were reported previously [52]. Thus we assume that the methods used had no effects on the behavior of the animals and that the data after saline injection on ED1 can be used as a control in the MPD experimental groups to evaluate the drug effects.

The behavioral data for the experimental groups is displayed in Figure 2. Figure 2(Aa) summarizes the data obtained from all the animals $(\mathrm{N}=36)$ that received injections of $0.6 \mathrm{mg} / \mathrm{kg} \mathrm{MPD}$, and no significant change was found after either acute or chronic exposure to MPD using the ANOVA for the group.

Figure 2(Ab) summarizes the data from those animals $(\mathrm{N}=22)$ that were individually evaluated and each exhibiting significant $(\mathrm{P}<0.05)$ increases in locomotion at ED10 post-MPD exposure compared to post-MPD exposure on ED1 (i.e. they exhibited behavioral sensitization). The acute effect of $0.6 \mathrm{mg} / \mathrm{kg}$ MPD using the ANOVA failed to show significant modulations of the locomotor activity. The ED10 baseline activity after six daily MPD injections and three washout days remained the same as compared to ED1 baseline activity. MPD exposure at ED10 elicits in this group of animals significant $(\mathrm{P}<0.05)$ elevation in their locomotor activity compared to ED1 post MPD exposure (Figure 2(Ab)).

The 14 animals that exhibited tolerance when individually evaluated were grouped together in Figure 2(Ac), As a group, they showed significant $(\mathrm{P}<0.05)$ changes following acute MPD exposure, while their baseline activity at ED10 compared to ED1 baseline was about the same. The activity following MPD exposure at ED10 was compared to that of ED1 post MPD exposure exhibit significant $(\mathrm{P}<0.05)$ attenuation effect on locomotion, as a group using ANOVA.

All of the animals $(\mathrm{N}=39)$ that received $2.5 \mathrm{mg} / \mathrm{kg}$ MPD are presented in Figure 2(Ba) and exhibited significant $(\mathrm{P}<0.05)$ alteration in their HA following acute MPD exposure. The ED10 baseline activity compared to ED1 baseline activity and the activity following rechallenge of $2.5 \mathrm{mg} / \mathrm{kg}$ MPD exposure at ED10 compared to the effect of $2.5 \mathrm{mg} / \mathrm{kg}$ MPD at ED1 exhibited no significant changes.

The individual animals that each exhibited behavioral sensitization $(\mathrm{N}=30)$ were summed as a group (Figure $2(\mathrm{Bb})$ ), and showed significant $(\mathrm{P}<0.05)$ increases in locomotion following acute $2.5 \mathrm{mg} / \mathrm{kg}$ MPD exposure and their baseline activity at ED10 after six daily MPD administrations and three washout days exhibit sig 
Adolescent Horizontal Activity (HA)

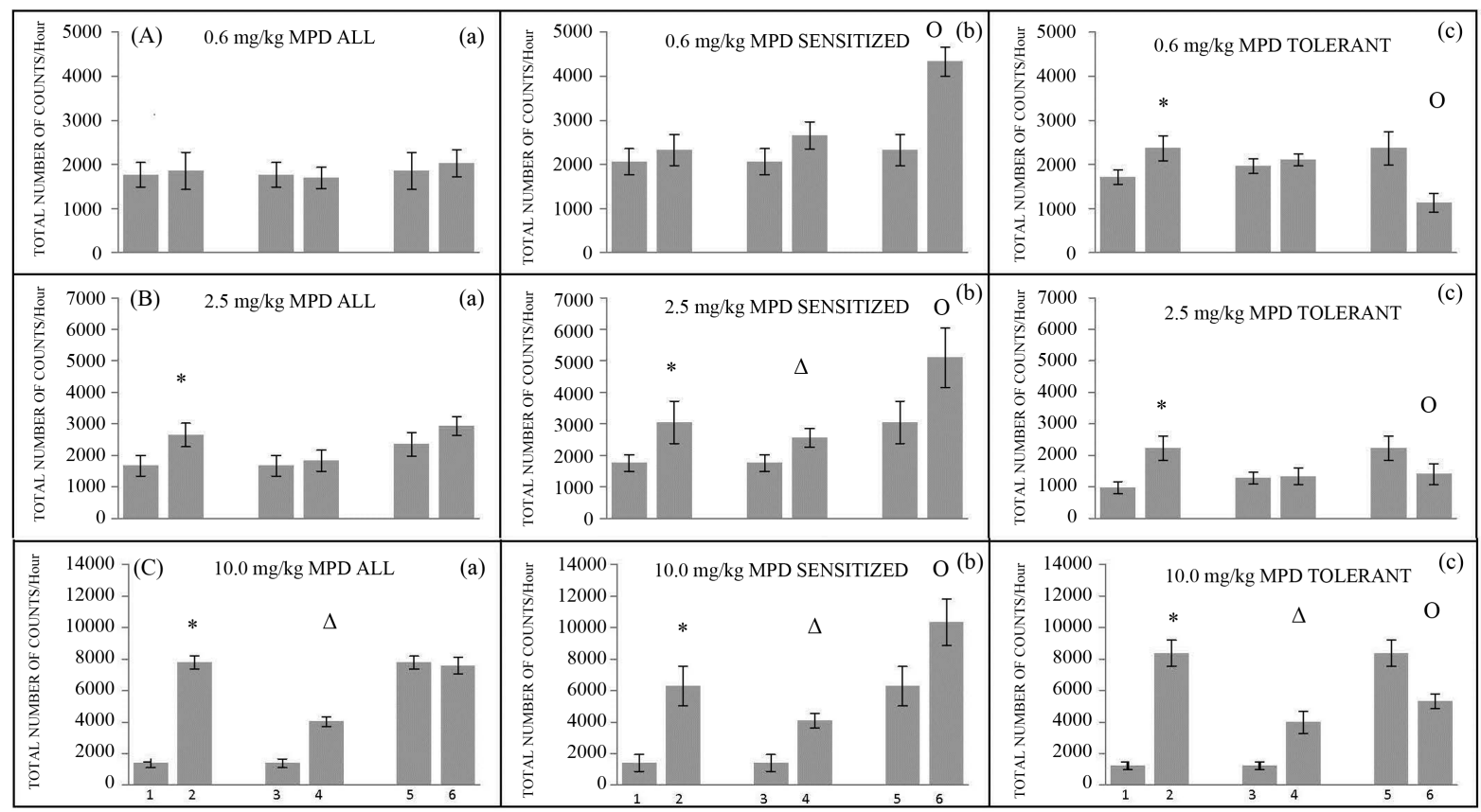

Figure 2. The figure summarizes the dose responses $(0.6,2.5$, and $10.0 \mathrm{mg} / \mathrm{kg})$ effect of methylphenidate (MPD) on horizontal activity count. In (A), (B) and (C) are the data following 0.6, 2.5, and 10.0 MPD respectively. Under (A), (B) and (C) are the data of all the animals (All), of animals expressing behavioral sensitization (sensitized) and of animals expressing behavioral tolerance (tolerant) respectively. The numbers under the column ( $\mathrm{x}$-axis) summarizes the following comparisons 1 = experimental day (ED1) baseline; 2 = ED1 activity post acute MPD exposure; $3=$ ED1 baseline activity; $4=$ ED10 baseline activity; $5=$ ED1 activity post acute MPD exposure and $6=$ ED10 activity post MPD rechallenge. *indicates significant different comparing the initial effect of MPD at ED1 to ED1 baseline; ${ }^{\star}$ indicates significant differences comparing the ED10 baseline after six daily injections and three washout days to ED1 baseline, and ${ }^{\Delta}$-indicates significant differences between the chronic effect of MPD given at ED10 compared to that observed at ED1 following the MPD initial effect. Significance was set at $\mathrm{P}<0.05$.

nificant $(\mathrm{P}<0.05)$ increases in their ED10 baseline activity compared to ED1 baseline activity. MPD rechallenge at ED10 elicited significant $(\mathrm{P}<0.05)$ further increases in locomotor behavior compared to the initial MPD effect at ED1 (Figure 2(Bb)).

The individual animals that exhibited behavioral tolerance after $2.5 \mathrm{mg} / \mathrm{kg}$ MPD exposure $(\mathrm{N}=9)$ were summarized in Figure 2 $(\mathrm{Bc})$ they showed significant $(\mathrm{P}<0.05)$ increases in their locomotor activity to acute MPD exposure but no significant change in their ED10 baseline locomotor activity compared to ED1 baseline locomotor activity. A rechallenge of MPD at ED10 compared to the initial MPD effects at ED1, these animals exhibited significant $(\mathrm{P}<0.05)$ decreases in locomotor activity (Figure 2(Bc)).

All of the animals that were exposed to $10 \mathrm{mg} / \mathrm{kg}$ MPD are presented in Figure 2(Da). This group $(\mathrm{N}=41)$ showed a significant $(\mathrm{P}<0.05)$ increase in locomotor behavior following acute MPD exposure. The baseline activity at ED10 compared to baseline activity at ED1 was significantly $(\mathrm{P}<0.05)$ elevated. MPD rechallenge at ED10 compared to MPD acute effect was not significantly elevated (Figure 2(Da)).

The individual animals that each exhibited behavioral sensitization are presented as a group in Figure 2(Db) $(\mathrm{N}=21)$. This group exhibits significant $(\mathrm{P}<0.05)$ increases in locomotor activity following acute MPD exposure and significant increases in their ED10 baseline locomotor activity compared to ED1 baseline. MPD rechallenge at ED10 elicits further significant $(\mathrm{P}<0.05)$ increases compared to MPD effects at ED1 (Figure $2(\mathrm{Cb}))$.

The individual animals that exhibited behavioral tolerance following $10.0 \mathrm{mg} / \mathrm{kg}$ MPD exposure are shown as a group in Figure 2(Dc) $(\mathrm{N}=20)$. This group showed significant $(\mathrm{P}<0.05)$ increases in locomotor activity following acute MPD exposure, as well as a significant increase in baseline locomotor activity of ED10 compared to ED1 baseline. After rechallenge of $10.0 \mathrm{mg} / \mathrm{kg}$ MPD at ED10, these animals exhibited a significant $(\mathrm{P}<0.05)$ 
decrease in their locomotor activity, compared to the activity following the initial $10.0 \mathrm{mg} / \mathrm{kg}$ MPD given at ED1 (Figure 2(Cc)). Similar observations with some not significant fluctuations were observed for the stereotypic movements.

The objective of analyzing the behavioral recording for each animal was to determine which animal expressed behavioral sensitization or tolerance by comparing their locomotor activity on ED10 post-MPD treatment to the locomotor activity on ED1 after the initial MPD exposure.

\subsection{Neurophysiological Results}

Four hundred and fifty-nine PFC units from 385 electrodes both histologically identified as being in the PFC and exhibiting similar spike amplitude and pattern at ED1 and ED10 were evaluated. Forty five, 147, 165, and 102 PFC units were recorded following saline, $0.6,2.5$, and $10.0 \mathrm{mg} / \mathrm{kg}$ i.p. MPD respectively.

\subsubsection{Effects of Saline on PFC Units}

Forty-five PFC units were recorded from the control group i.e., following saline injection at ED1 and ED10. At ED1, saline injection elicited increased activity to two (4\%) PFC units and decreased activity to three (7\%) PFC units, in $40 / 45(89 \%)$ of the PFC units saline failed to alter their neuronal firing rates. The baseline activity of 96\% (43/45) of the PFC units at ED10 after six consecutive daily saline injection and three washout days remained the same as recorded at ED1. Saline rechallenge injection at ED10 compared to activity post saline injection at ED1 or at ED10 failed to alter the PFC neuronal activity in 91\% (41/45) of the units (Table 2(A), saline). In short, similar firing patterns were recorded for all instances after saline administration with minor non significant fluctuation, suggesting that the methodology of the experiment itself did not alter significantly the firing rate of the PFC neuronal activity. Thus any significant changes in firing rate following MPD exposure

Table 2. The table summarizes the prefrontal cortex (PFC) unit responses to acute (day 1) and chronic (Day 10) of MPD exposure. Under doses-the MPD dose; under N-the number of PFC units recorded in each of the groups. Under acute-Day 1 is the number of PFC units responding to the initial (acute) treatment versus baseline by decreasing $(\downarrow)$ or increase $(\uparrow)$ or no effects $(\neq)$ and their \% response from the PFC neuronal population following the treatment in brackets. Under baseline day 10 are the statistical calculations of the baseline activity at experimental (ED) 10 after six daily treatments and three washout days compared to ED1 baseline neuronal activity. Under chronic-Day 10 is the effect of MPD rechallenge at ED10 compared to that obtained at ED1 following MPD exposure.

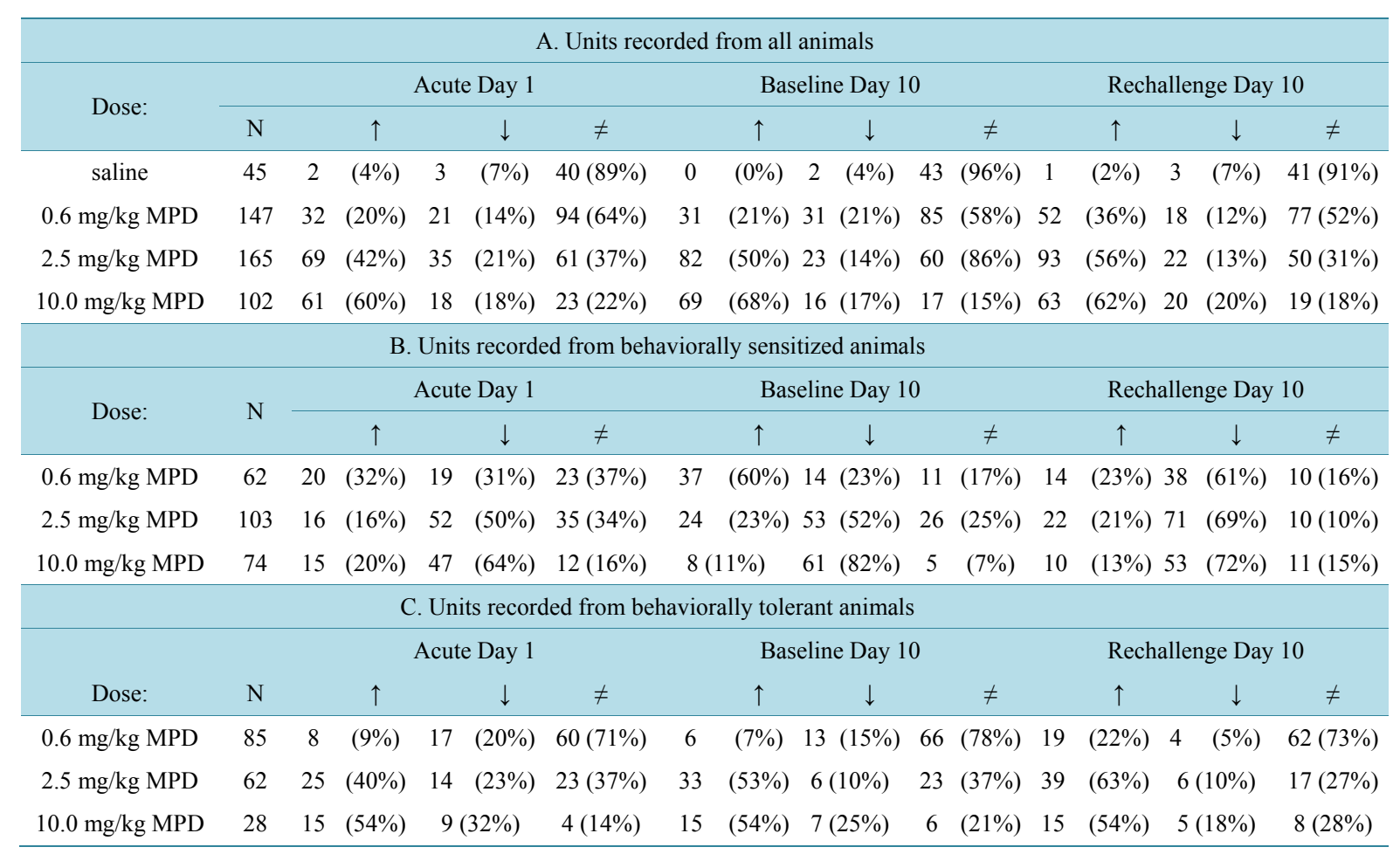


compared to saline can be considered as being due to the effect of the drug.

\subsubsection{Effect of $0.6 \mathrm{mg} / \mathrm{kg}$ MPD on PFC Units Recorded from All the Animals (Table 2(A))}

A total of 147 PFC units were recorded following the acute and chronic administration of $0.6 \mathrm{mg} / \mathrm{kg}$ MPD. After acute administration of MPD, only 53/147 (36\%) of the PFC units responded significantly $(\mathrm{P}<0.05)$ to the 0.6 $\mathrm{mg} / \mathrm{kg}$ MPD with a majority of the responsive units $60 \%$ (32/53) increasing in their firing rate (Table 2(A) Acute and Figure 3).

When the baseline neuronal activity of ED10 was compared to the baseline recorded on ED1 (Figure 4), $62 / 147$ (42\%) of the PFC units exhibited a significant change in their baseline activity as a result of six daily 0.6 $\mathrm{mg} / \mathrm{kg}$ MPD injections and three washout days. Of these units, half of them exhibited an increase (Figure 4(A)) and the other half exhibited a decrease in their baseline neuronal activity (Table 2(A) Baseline and Figure 4(B)).

Following MPD rechallenge on ED10, 70/147 (48\%) units modulated (responded) significantly $(\mathrm{P}<0.05)$ their firing rate, with 52/70 (74\%) of the responding PFC units exhibiting an increase in their activity (Table 2(A) Rechallenge and Figure 5) at ED10 compared to the activity following MPD at ED1.

\subsubsection{PFC Unit Activity Recorded from Animals Exhibiting Behavioral Sensitization in Response to Chronic $0.6 \mathrm{mg} / \mathrm{kg}$ MPD (Table 2(B))}

From the 147 PFC units recorded, 62 were from rats that exhibited behavioral sensitization in response to chronic $0.6 \mathrm{mg} / \mathrm{kg}$ MPD (Table 2(B)). After acute administration of $0.6 \mathrm{mg} / \mathrm{kg}$ MPD on ED1, 39 of the 62 units (63\%) responded significantly $(\mathrm{P}<0.05)$ by changing their firing rates, with half showing significantly $(\mathrm{P}<0.05)$ increased activity and the other half with significantly $(\mathrm{P}<0.05)$ decreased activity (Table 2(B) Acute day 1$)$.

When the baseline activity of ED10 was compared with ED1 baseline activity, 51/62 PFC units (82\%) demonstrated a significant $(\mathrm{P}<0.05)$ change in their baseline activity, with $37 / 51(73 \%)$ showing a significant $(\mathrm{P}<$

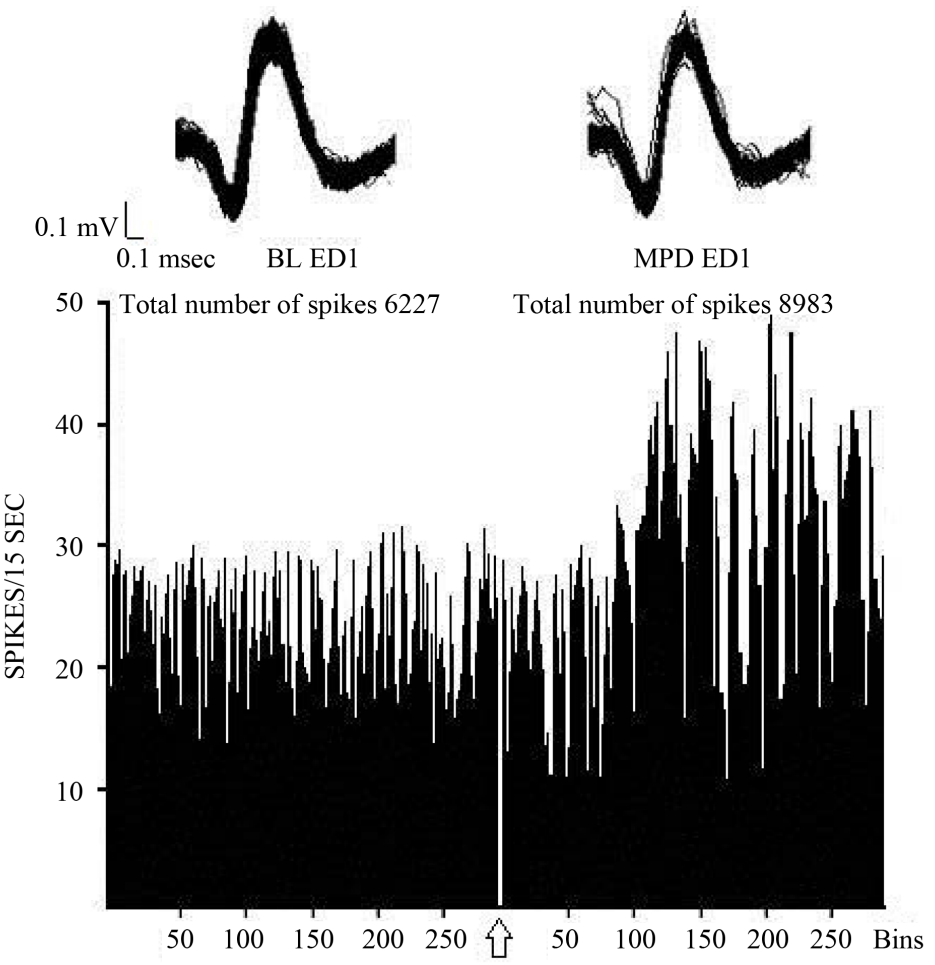

Figure 3. Representative sequential frequency histogram of one prefrontal cortex (PFC) unit before (baseline BL ED1) and following acute $0.6 \mathrm{mg} / \mathrm{kg}$ MPD (MPD ED1). Arrow indicates the time of MPD injection. Above each histogram is the total number of spikes/60 min. In A-PFC units responded to MPD by increase in their firing rates. 

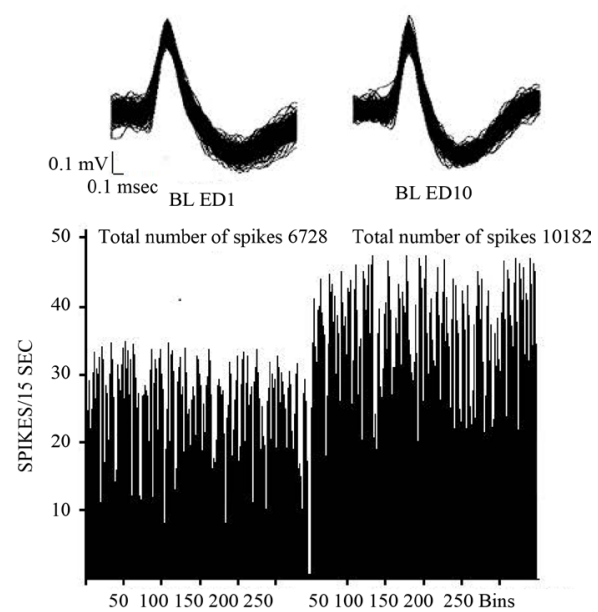

(A)

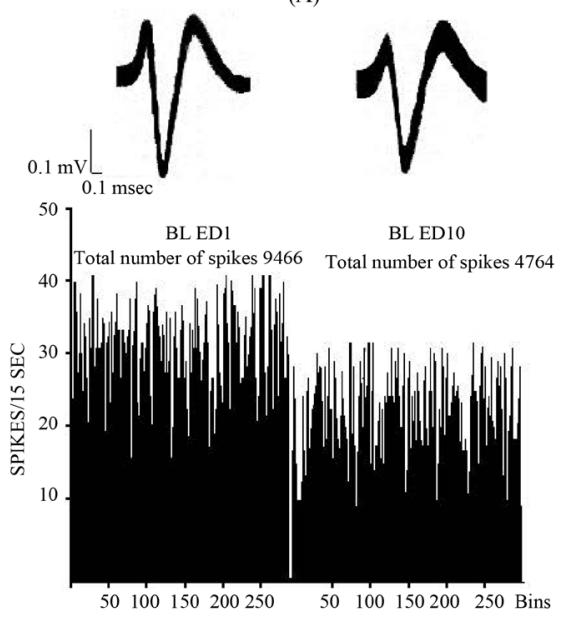

(B)

Figure 4. Representative sequential histogram of two PFC units comparing the baseline (BL) activity at ED10 (BL ED10) after six daily $0.6 \mathrm{mg} / \mathrm{kg}$ MPD and three washout days with the baseline activity obtained at ED1 (BL ED1). Above each histogram are superimposed 50 spikes aiming to show that the spike amplitude and pattern activity analyzing at ED1 was the same at ED10. The numbers under the spike shapes are the total number of spikes/60 minutes. In A are PFC units that exhibit increases in ED10 BL compared to ED1 BL. In B are the PFC units that exhibit decreases in ED10 BL compared to ED1 BL.

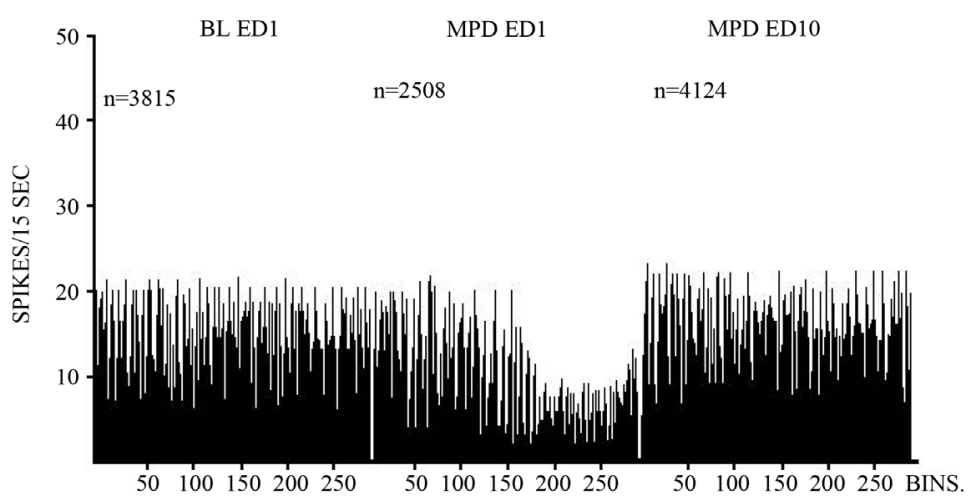

Figure 5. Representative sequential frequency histograms of one PFC units before (ED1 BL), after acute MPD (MPD ED1) and after rechallenge $0.6 \mathrm{mg} / \mathrm{kg}$ MPD at ED10 (MPD ED10). The figure shows acute MPD elicits a decrease in firing rates and MPD rechallenge at ED10 elicits an increase in firing rates when compared to the initial effect of MPD at ED1 (i.e. electrophysiological sensitization). 
0.05 ) decrease in their baseline activity after six daily $0.6 \mathrm{mg} / \mathrm{kg}$ MPD injections and three washout days (Table 2(B) Baseline ED10).

After $0.6 \mathrm{mg} / \mathrm{kg}$ MPD rechallenge on ED10 compared to activity post-MPD at ED1, 52/62 (84\%) units responded by significantly $(\mathrm{P}<0.05)$ changing their firing rate, with $38 / 52(73 \%)$ exhibiting a significant $(\mathrm{P}<$ 0.05 ) increase in their firing rates at ED10 compared to ED1 post $0.6 \mathrm{mg} / \mathrm{kg}$ MPD exposure (Table 2(B) Rechallenge day 10).

\subsubsection{PFC Unit Activity Recorded from Animals Exhibiting Behavioral Tolerance in Response to Chronic $0.6 \mathrm{mg} / \mathrm{kg}$ MPD (Table 2(C))}

From the $147 \mathrm{PFC}$ units recorded, 85 units were recorded from the animals that exhibited behavioral tolerance to chronic $0.6 \mathrm{mg} / \mathrm{kg}$ MPD. From these 85 units (Table 2(C)) only $25(29 \%)$ units responded significantly $(\mathrm{P}<$ $0.05)$ to the MPD exposure at ED1. Out of these responding PFC units, the majority 17/25 (68\%) showed a significantly responded to the drug by decreasing their firing rates (Table 2(C) Acute day 1).

When comparing the baseline activity of these PFC units on ED10 to that of ED1, 19/85 (22\%) units showed a significant $(\mathrm{P}<0.05)$ change in baseline neuronal activity. Of these 19 PFC units, the majority 13/19 (68\%) showed a significantly decrease in their baseline activity $(\mathrm{P}<0.05)($ Table 2(C) Baseline day 10).

After the rechallenge with $0.6 \mathrm{mg} / \mathrm{kg}$ MPD on ED10, 23/85 (27\%) units responded significantly $(\mathrm{P}<0.05)$ by changing their firing rates, from the responding PFC units 19/23 (83\%) showed a significant $(\mathrm{P}<0.05)$ decrease in neuronal activity at ED10 compared to ED1 activity post-MPD exposure (Table 2(C) Rechallenge day 10).

\subsubsection{Effect of $2.5 \mathrm{mg} / \mathrm{kg}$ MPD on PFC Units Recorded from All the Animals (Table 2(A))}

One hundred and sixty-five PFC units were recorded following acute and chronic $2.5 \mathrm{mg} / \mathrm{kg}$ doses of MPD. On ED1 following acute administration of MPD, 104/165 (63\%) of the units responded significantly $(\mathrm{P}<0.05)$ to acute MPD injection by changing their firing rate with the majority 69/104 (66\%) of the responding PFC units exhibiting significant $(\mathrm{P}<0.05)$ increases in their neuronal firing rate (Table 2(A) Acute day 1).

When comparing the baseline activity on ED10 to the baseline measured on ED1, 105/165 (64\%) of PFC units exhibited significant $(\mathrm{P}<0.05)$ changes in their baseline neuronal activity, and the majority 82/105 $(78 \%)$ showing significant $(\mathrm{P}<0.05)$ increases in their baseline neuronal activity (Table 2(A) Baseline).

MPD rechallenge at ED10 with $2.5 \mathrm{mg} / \mathrm{kg}$ MPD, significantly $(\mathrm{P}<0.05)$ modified $115 / 165(70 \%) \mathrm{PFC}$ units with 93/115 $(81 \%)$ of the responding units showing further significant $(\mathrm{P}<0.05)$ increases in their firing rate (Table 2(A) Rechallenge) following $2.5 \mathrm{mg} / \mathrm{kg}$ MPD rechallenge compared to the effect of MPD on ED1.

\subsubsection{PFC Unit Activity Recorded from Animals Exhibiting Behavioral Sensitization in Response to Chronic $2.5 \mathrm{mg} / \mathrm{kg}$ MPD (Table 2(B))}

One hundred and three PFC units were recorded from animals that showed behavioral sensitization to chronic $2.5 \mathrm{mg} / \mathrm{kg}$ MPD. On ED1, after acute administration of $2.5 \mathrm{mg} / \mathrm{kg}, 68 / 103(66 \%)$ of the PFC units responded significantly $(\mathrm{P}<0.05)$ by changing their firing rate with the majority $52 / 68(76 \%)$ of the responding PFC units exhibiting increased firing rates (Table 2(B) Acute day 1).

When the baseline activity of ED10 was compared to ED1 baseline, 77/103 (75\%) PFC units showed significant $(\mathrm{P}<0.05)$ changes in their baseline activity, with the majority of the units 53/77 $(69 \%)$ exhibiting significant $(\mathrm{P}<0.05)$ increases in their baseline firing rates (Table $2(\mathrm{~B})$ Baseline day 10$)$.

MPD rechallenge at ED10 compared to the initial MPD exposure at ED1 significantly $(\mathrm{P}<0.05)$ modified 93/103 (90\%) of PFC units, with 71/93 (76\%) of the responsive units exhibiting significant $(\mathrm{P}<0.05)$ increases in their neuronal activity at ED10, compared to ED1 post-MPD exposure (Table 2(B) Rechallenge day 10).

\subsubsection{PFC Unit Activity Recorded from Animals Exhibiting Behavioral Tolerance in Response to Chronic $2.5 \mathrm{mg} / \mathrm{kg}$ MPD (Table 2(C))}

From the 165 PFC units recorded, 62 units were recorded from animals exhibiting behavioral tolerance to chronic MPD exposure. On ED1, after acute administration of $2.5 \mathrm{mg} / \mathrm{kg} \mathrm{MPD}, 39 / 62(63 \%)$ of these PFC units responded significantly $(\mathrm{P}<0.05)$ to the drug by changing their firing rate, the majority $25 / 39(64 \%)$ of these responding PFC units showing an increase in their neuronal activity (Table 2(C) Acute day 1) following acute MPD exposure.

When the baseline activity of ED10 was compared with ED1 baseline neuronal activity, 39/62 (63\%) PFC 
units significantly $(\mathrm{P}<0.05)$ modified their baseline activity with 33/39 $(85 \%)$ PFC units showing an increase in their baseline neuronal activity in ED10 compared to ED1 (Table 2(C) Baseline day 10).

MPD $2.5 \mathrm{mg} / \mathrm{kg}$ rechallenge at ED10 significantly $(\mathrm{P}<0.05)$ modified 45/62 $(73 \%)$ of PFC units with 39/45 (87\%), exhibiting a decrease in their neuronal activity following rechallenge $2.5 \mathrm{mg} / \mathrm{kg}$ MPD exposure (Table 2(C) Rechallenge).

\subsubsection{Effect of $10.0 \mathrm{mg} / \mathrm{kg}$ MPD on PFC Units Recorded from All the Animals (Table 2(A))}

A total of $102 \mathrm{PFC}$ units were recorded following the acute and chronic administration of $10.0 \mathrm{mg} / \mathrm{kg}$ MPD. After acute MPD administration, 79/102 (75\%) PFC units responded significantly $(\mathrm{P}<0.05)$ to the $10.0 \mathrm{mg} / \mathrm{kg}$ MPD with a majority of the responsive units 61/79 $(77 \%)$ exhibiting a significant $(\mathrm{P}<0.05)$ an increase in firing rates (Table 2(A) Acute day 1).

When the baseline neuronal activity of ED10 was compared to the baseline recorded on ED1, 85/102 (83\%) PFC units significantly $(P<0.05)$ changed their baseline activity. Of these units, a majority of them $69 / 85(81 \%)$ displayed significantly $(\mathrm{P}<0.05)$ increase in their neuronal activity (Table 2(A) Baseline day 10).

Following rechallenge with $10.0 \mathrm{mg} / \mathrm{kg}$ MPD on ED10, 83/102 (81\%) PFC units responded significantly ( $\mathrm{P}<$ $0.05)$ by changing their firing rate, and the majority of the responsive units $63 / 83(76 \%)$ exhibited an increase in their neuronal activity (Table 2(A) Rechallenge day 10).

\subsubsection{PFC Unit Activity Recorded from Animals Exhibiting Behavioral Sensitization in Response to Chronic $10.0 \mathrm{mg} / \mathrm{kg}$ MPD (Table 2(B))}

From the 102 PFC units recorded, 74 units were from animals that showed significant signs of behavioral sensitization. On ED1, after acute administration of $10.0 \mathrm{mg} / \mathrm{kg}, 62 / 74(84 \%)$ of these PFC units responded significantly $(\mathrm{P}<0.05)$ by changing their firing rates with $47 / 74(64 \%)$ of the responding units exhibiting significant $(\mathrm{P}<$ 0.05 ) increases in their firing rates (Table 2(B) Acute day1).

When the baseline activity of ED10 was compared to ED1 baseline activity, 69/74 (93\%) PFC units significantly $(\mathrm{P}<0.05)$ changed their baseline activity with $61 / 69(88 \%)$ of these responding units showing significant $(\mathrm{P}<0.05)$ increases in their firing rates (Table 2(B) Baseline day 10$)$.

After rechallenge with $10.0 \mathrm{mg} / \mathrm{kg}$ MPD at ED10, 63/74 $(85 \%)$ units responded significantly $(\mathrm{P}<0.05)$ to the drug by changing their firing rate, with $53 / 63(84 \%)$ of the responsive PFC units exhibiting significant $(\mathrm{P}<$ 0.05) increases in their neuronal activity (Table 2(B) Rechallenge day 10).

\subsubsection{PFC Unit Activity Recorded from Animals Exhibiting Behavioral Tolerance in Response to Chronic $10.0 \mathrm{mg} / \mathrm{kg}$ MPD (Table 2(C))}

Of the $102 \mathrm{PFC}$ units recorded following $10 \mathrm{mg} / \mathrm{kg}$ MPD, $28 \mathrm{PFC}$ units were recorded from animals exhibiting signs of behavioral tolerance. On ED1, after acute administration of $10.0 \mathrm{mg} / \mathrm{kg} \mathrm{MPD}, 24 / 28$ (86\%) PFC units responded significantly $(\mathrm{P}<0.05)$ to the drug, with $15 / 24(62 \%)$ of the responsive PFC units showing significant $(\mathrm{P}<0.05)$ increases in their neuronal activity (Table 2(C) Acute day 1$)$.

When the baseline activity of ED10 was compared with that of ED1 baseline in the animal group exposed to $10.0 \mathrm{mg} / \mathrm{kg}$ MPD, 22/28 (79\%) PFC units displayed significant $(\mathrm{P}<0.05)$ changes in their baseline activity with $15 / 22(68 \%)$ of the responsive PFC units showing significant $(\mathrm{P}<0.05)$ increase in their neuronal activity (Table 2(C) Baseline day 10).

On ED10, after the $10.0 \mathrm{mg} / \mathrm{kg}$ MPD rechallenge, 20/28 (71\%) PFC units responded significantly $(\mathrm{P}<0.05)$ to the drug by changing their firing rate, with $15 / 20(75 \%)$ of the responsive PFC units exhibiting significant $(\mathrm{P}<$ 0.05 ) decreases in their neuronal activity (Table 2(C) Rechallenge day 10) at ED10 compared to the activity of ED 1 post MPD exposure.

\subsection{Statistical Comparison of Groups}

A log linear analysis was used to determine the relationship between dose, behavior, and firing patterns (increase/decrease firing rate post MPD exposure) for each group $(0.6,2.5$, and $10.0 \mathrm{mg} / \mathrm{kg} \mathrm{MPD}$ ) with significance set at $(\mathrm{P}<0.05)$. The PFC neuronal population exposed to $0.6 \mathrm{mg} / \mathrm{kg}$ MPD recorded from animals that exhibited behavioral tolerance responded to MPD exposure with significance $\left(\mathrm{X}^{2}: 4.03 \mathrm{P}=0.04\right)$ difference compared to PFC neuronal population recorded from animals exhibiting behavioral sensitization. Moreover, the re- 
sponse ratio between increase/decrease firing rate post chronic MPD exposure of PFC neuronal population recorded from animals that exhibited behavioral sensitization to either 2.5 , or $10.0 \mathrm{mg} / \mathrm{kg}$ MPD dose showed highly significantly $\left(\mathrm{X}^{2}: 14.38 ; \mathrm{P}=0.0001\right)$, and $\left(\mathrm{X}^{2}: 11.81 ; \mathrm{P}=0.001\right)$ different compared to the responses of the PFC neuronal population recorded from animals that exhibited behavioral tolerance, respectively.

\section{Discussion}

The PFC plays an important role in the circuitry of the brain involved with working memory, regulating attention, and the ability to suppress irrelevant thoughts [1] [4]. Unfortunately the PFC is potentially abnormal in individuals with ADHD [4]. With an estimated prevalence of $8.7 \%$ among US children, ADHD is a common disorder that often persists into adulthood [14] [15]. MPD is highly prescribed to those with ADHD [12] [53], and thought to be misused by a wide range of individuals both with and without ADHD [54]. In a prior experiment investigating the effect of acute and chronic $2.5 \mathrm{mg} / \mathrm{kg}$ MPD administered to the adult rat, all of the PFC units following acute MPD exposure exhibited significant changes in their firing rates, with the majority of them exhibiting an increase in activity. After six daily $2.5 \mathrm{mg} / \mathrm{kg}$ MPD exposures and three washout days, the baseline neuronal activity of these rats was recorded again on experimental day 10 (ED10). Significant changes compared to the previous baseline recorded at ED1 were observed [41]. A similar experimental protocol using MPD dose response protocols $(0.6,2.5$, and $10.0 \mathrm{mg} / \mathrm{kg}$ MPD) in adolescent rats was used in this study.

Due to developmental changes that take place within the brain over the course of adolescence, such as synaptic morphology, receptor, and spine density changes [17] [18] [20] [55] [56], there is a concern that MPD exposure in adolescents may affect the developing brain during this time. The above study indicated the need to investigate the responses of both normal and ADHD-affected individuals on animal models to acute and chronic MPD exposure with respect to different age groups. Moreover, the central nervous system in adolescents is in a developmental state going through the process of increases and decreases in its neutropil such as dendritic branches, receptor density pruning, and neuronal pathway reorganization [55] [56]. Thus, this study uses adolescent rats since most studies have used adult subjects, while the majority of MPD users are adolescent.

The main findings of this study include the following: 1) the acute dose of $0.6 \mathrm{mg} / \mathrm{kg}$ MPD in adolescent rats failed to elicit significant increases in locomotor activity of adolescent SD rats, while eliciting increased locomotion of the adult SD rats [45]-[47]; 2) the acute 2.5, and $10.0 \mathrm{mg} / \mathrm{kg}$ MPD elicited increases in the locomotor activity of the adolescent rats in a dose dependent characteristic. With increasing MPD doses, a further increase in locomotion was observed; 3 ) when all the animals were combined into one group, chronic $0.6,2.5$, and 10.0 $\mathrm{mg} / \mathrm{kg}$ MPD failed to elicit either behavioral tolerance or behavioral sensitization in adolescent rats (Figure 2(Aa)-(Ca)); 4) when the rats were analyzed according to each individual response to chronic MPD the doses of 0.6, 2.5, and $10.0 \mathrm{mg} / \mathrm{kg}$ MPD elicited behavioral sensitization in some animals (Figures 2(Ab)-(Cb)) and behavioral tolerance in others (Figures 2(Ab)-(Cb)), thus supporting our first hypothesis; 5) the ED10 baseline activity after six daily MPD exposures and three washout days was significantly modulated, indicating expectation to get the drug and/or the expression of withdrawal behavior [29] [39]; 6) the PFC neuronal responses to MPD exposure recorded from animals expressing behavioral sensitization was significantly different from those PFC neuronal responses to MPD exposure recorded from animals expressing behavioral tolerance, thus supporting our second hypothesis.

The PFC contains pyramidal glutaminergic neurons, which are primary output neurons, as well as GABAergic non-pyramidal interneurons [57]. Several neurotransmitter systems regulate these PFC neurons, including GABAergic, dopaminergic, serotonergic, noradrenergic, glutamatergic, cholinergic, and peptidergic afferents. Each system has varied interactions with PFC neurons that, if altered by either internal or external input, can produce changes in PFC neuronal activity and animal behavioral activity, as well as potentially induce sensitization or tolerance ([58] Steketee, 2003). In addition, the PFC receives dopaminergic innervation from the VTA and norandrenergic innervation from the locus coeruleus, which also seems to increase monoamine release within the PFC (Lewis and Morrison, 1989; [58] Steketee, 2003). Ascending DA neurons synapse onto pyramidal glutamate neurons and GABAergic interneurons ([58] Steketee, 2003). Stimulants such as MPD are thought to bind mainly to dopamine and norepinephrine transporters and thus increase the available neurotransmitter concentrations that result in increasing the concentrations of DA and NE in the synaptic cleft to act upon D1, D2, and NE alpha-2A receptors within the PFC [2] [57] [59]-[63] causing activation of PFC neuronal activity and subsequently behavioral modulation. As the drug is metabolized, behavior and neuronal activity return to 
baseline. MPD effects on dopamine and norepinephrine are believed to regulate the activity of the PFC interneurons, as well as glutaminergic efferents to the limbic system, producing its effects on attention span and behavior [2] [64]. There are at least two distinct DA receptor populations in the PFC [21], each with its own distinct profile of activation. Psychostimulants such as MPD binding to D1 DA receptors results will result in excitation and binding to D2 DA receptors will result in attenuation of activity, respectively [62] [65]-[66].

In this study, we proposed the following chain of events following MPD exposure: 1) initially, MPD binds mainly to dopamine transporters, thereby preventing the reuptake of DA from the synaptic cleft to the presynaptic terminals that resulting in an increase in DA concentration in the synaptic cleft [27] [67]-[68]; 2) the increase in DA levels results in either increases or decreases in PFC neuronal firing rates, depending on the type of receptors (e.g. D1 or D2 DA receptors) the drug activated; 3) these activations modulate the neuronal baseline activity and the neuronal activity in turn modulates the animal's behavior; 4) as the acute exposure of MPD is metabolized, DA levels return to predrug levels and both the neuronal activity and behavior return to its baseline. Following repetitive exposure to MPD, however, the above chain of events is repeated, and this repetitive (chronic) drug exposure elicits cellular and molecular plasticity, such as alterations in protein synthesis, alteration in receptors and synaptic spine density, as well as neuropil morphology modulation [55] [56] [65] [66]. This plasticity is the underlying mechanism for the neuronal response (i.e., increase or decrease) to MPD, as well as whether behavioral sensitization or tolerance will occur.

The above mentioned studies regarding neuroplasticity resulting from repetitive MPD exposure can explain our neuronal observation, electrodes recording from PFC units with D1 DA receptors and their neutropil was increased [55] [56] following chronic MPD exposure will respond to chronic MPD by further increasing their firing rate as compared to the initial response, while electrodes recording from neurons with D2 DA receptors that the chronic MPD exposure resulted in a decrease its neuropil will exhibit a decrease in firing rates to rechallenge MPD exposure compared to the initial response, respectively.

The overall results of all the PFC neuronal activity with no correlation to the animals' behavioral response to chronic MPD exposure demonstrates that some units respond electrophysiologically by increasing their firing rates and others by decreasing their firing rate. However, when the animals were divided based on their behavioral response to chronic MPD exposure, the majority of the PFC units recorded from behavioral tolerance animals responded to the drug by attenuation of their neuronal firing rate, following MPD rechallenge at ED10 compared to the activity following the initial MPD exposure at ED1. In contrast, those PFC neurons recorded from animals expressing behavioral sensitization responded to the drug at ED10 by increasing their firing rates compared to the initial MPD exposure at ED1. Why do some of the PFC units respond to the same MPD dose by increased activity and the others by attenuation of their neuronal activity, and why do animals express behavioral tolerance and others behavioral sensitization? These differences may lie in the distribution and density of D1 and D2 receptors within a particular structure [57] [59] [62] [69]. There could also be a dose dependent MPD exposure relationship of D1 or D2 DA receptor activation. For example, "lower" MPD doses activate mainly the D1 DA receptors in the PFC, resulting in behavioral sensitization, while higher MPD dose exposure activates mainly the D2 DA receptors that results in behavioral tolerance, respectively [62] [69]. Intrinsic differences between individual rats, as well as differences between the ratios of D1 or D2 receptors on the neurons that were recorded will result in PFC different subpopulation response profiles. [2] [70], also another possible interpretation of this observation, in addition to the receptors themselves acting acutely is the role of the vesicular monoamine transporter (VMAT2), an intracellular molecule that stores and facilitates the movement of intracellular DA in the presynaptic neuron. Its molecular concentration exhibits a transient increase following acute MPD exposure, possibly explaining the increase in neural activity following acute MPD exposure [63].

When psychostimulants such as MPD are given repeatedly, longer-lasting changes begin to occur. Chronic psychostimulant administration increases the length of dendrites and branches in PFC neurons [70]-[72], as well as affects other changes in neuroarchitecture, such as neutropil plasticity and spine morphology [56] [70] It also elicits an increase in extracellular signal-related kinase (ERK) phosphorylation [73] that increases the levels of deltaFosB in the nucleus accumbens, and potentially other areas such as the PFC, resulting in an upregulation of GluR2 AMPA receptor subunits that may contribute to increased excitability in the region [66]. Another molecule that is upregulated by chronic psychostimulant exposure is the cAMP response element binding protein (CREB), which has been linked with behavioral tolerance [65] [66]. It is likely that these changes in morphology and molecular transcription factors, as a result of chronic psychostimulant exposure, contribute to the varied results of the experiment, particularly the baseline changes seen and the results following MPD rechallenge at 
ED10. The neuroarchitectural and molecular changes may also result in a change in the DA receptor densities, with the D2 receptors and CREB upregulation resulting in tolerance in some animals, while in other animals an increase in the D1 receptors and deltaFosB upregulation resulting in sensitization.

Previous studies [19] [57] of PFC neurons recorded following MPD given by i.v. injections in urethane anesthetized animals resulted in increased PFC neuronal activity. Conversely a selective DA D1 receptor antagonist, partially prevented the MPD effect, while local MPD application also increased the PFC neuronal activity and selective DA D1 receptors blocker attenuates this activity. The authors concluded that MPD activated the PFC firing rate via indirect DA D1 receptor or via indirect activation of DA D2 receptors [19] [57]. [74] recorded from the PFC in un-anesthetized adult male SD rats and reported that acute low MPD doses elicit excitation while higher MPD doses suppressed evoked discharges of the PFC neurons. [75] used whole cell patch clamp recordings from pyramidal PFC neurons in juvenile and adult SD rats reported that $1.0 \mathrm{mg} / \mathrm{kg} \mathrm{MPD}$, either a single dose or chronic, elicits significant depression in juveniles while the same dose exerted excitation in adults. The present study used different parameters then the cited studies above: 1) unanesthetized adolescents, freely behaving rats, were used to eliminate interference of anesthesia, which is known to MPD; 2) high impedance electrodes and recorded from selective (pyramidal) PFC neurons low impedance electrodes from non-selective neurons were recorded while other studies used; 3) with acute MPD exposure similar observations were reported while following chronic exposure. The difference may be due to different neurons, different MPD doses, and route of MPD administration, age, phenotype, and/or drug protocol.

Behaviorally, more rats were sensitized to chronic MPD exposure with doses between $0.6 \mathrm{mg} / \mathrm{kg}$ MPD and $2.5 \mathrm{mg} / \mathrm{kg}$ MPD exposure, and tolerance was noted in more rats given $10.0 \mathrm{mg} / \mathrm{kg}$ MPD exposure. It is possible that high doses of MPD exposure inhibit mechanisms that begin to dominate the response, causing the PFC to suppress behavior rather than to stimulate it as we see in the lower doses of MPD. With chronic higher concentrations of MPD treatment, neuropil morphology changes occur such as the decrease in length and the density of dendrites spines [55] [56] [65]. This neuroplasticity may cause a delay in signal transduction, resulting in less excitatory firing following MPD exposure i.e., tolerance. Sensitization at lower doses of MPD may be due to the changes in excitatory D1 receptor density as well as the upregulation of the GluR2 AMPA receptors due to the increase in deltaFosB that MPD and increases in the neuropil as a result of multiple MPD exposure and when MPD is given again excitation is exerted i.e., sensitization.

\section{Conclusions}

Pharmacological, molecular, and morphological studies mentioned earlier [2] [56] [57] [63] [71]-[73] make it possible to postulate the following mechanism of chronic MPD action. In some animals, the chronic exposure of the drug activated mainly the D1 DA receptors, triggering an increase in extracellular ERK phosphorylation, upregulating the transcription factor $\triangle$ Fos B, upregulating Glu R2 AMPA, increasing protein synthesis, increasing length and density of dendritic spines which result in more receptors and synapses that are activated by MPD exposure resulting in increased firing rates and increased locomotor activity, i.e., sensitization is expressed. In some animals the same drug treatment activated mainly the DA D2 receptors, upregulating the transcription factor CREB and decreased the neutropil, thus less receptors are activated and those that are activated exhibit a decrease in their firing rates when rechallenge of the drug is administered and compared to the initial response, i.e, expression of tolerance. Why some animals and some units expressed sensitization and others' tolerance needs to be elucidated.

Thus, we report the novel findings that two subpopulations of MPD response neurons exist in the PFC; some units express sensitization and others' tolerance, with the behavioral outcome that some animals demonstrate increased locomotor activity while others demonstrate decreased locomotor activity. Thus, acknowledging the predominate subpopulation of MPD response neurons in the PFC can predict behavioral outcomes and lead to therapeutic interventions to prevent addictions.

\section{Acknowledgements}

This study was supported by NIH DA R01 027222 grant. The authors wish to thank Catherine M Claussen, Heather Kregel, Dr. Claire Hulsebosch and Dr. Alice Chuang for statistical help. We wish to thank NIDA for their donation of methylphenidate. The authors declare no conflicts of interest. 


\section{References}

[1] Anderson, S.W., Bechara, A., Damasio, H., Tranel, D. and Damasio, A.R. (1999) Impairment of Social and Moral Behavior Related to Early Damage in Human Prefrontal Cortex. Nature Neuroscience, 2, 1032-1037. http://dx.doi.org/10.1038/12194

[2] Arnsten, A.F. (2006) Stimulants: Therapeutic Actions in ADHD. Neuropsychopharmacology, 31, 2376-2383. http://dx.doi.org/10.1038/sj.npp.1301164

[3] Dalley, J.W., Cardinal, R.N. and Robbins, T.W. (2004) Prefrontal Executive and Cognitive Functions in Rodents: Neural and Neurochemical Substrates. Neuroscience and Biobehavioral Reviews, 28, 771-784. http://dx.doi.org/10.1016/j.neubiorev.2004.09.006

[4] Wood, J.N. and Grafman, J. (2003) Human Prefrontal Cortex: Processing and Representational Perspectives. Nature Reviews Neuroscience, 4, 139-147. http://dx.doi.org/10.1038/nrn1033

[5] Greely, H., Sahakian, B., Harris, J., Kessler, R.C., Gazzaniga, M., Campbell, P. and Farah, M.J. (2008) Towards Responsible Use of Cognitive-Enhancing Drugs by the Healthy. Nature, 456, 702-705. http://dx.doi.org/10.1038/456702a

[6] Stix, G. (2009) Turbocharging the Brain. Scientific American, 301, 46-49. http://dx.doi.org/10.1038/scientificamerican1009-46

[7] Yang, P., Swann, A. and Dafny, N. (2006) Dose-Response Characteristics of Methylphenidate on Locomotor Behavior and on Sensory Evoked Potentials Recorded from the VTA, Nac, and PCF in Freely Behaving Rats. Behavioral and Brain Functions, 2, 3. http://dx.doi.org/10.1186/1744-9081-2-3

[8] Yang, P., Swann, A. and Dafny, N. (2006) Sensory-Evoked Potentials Recordings from the Ventral Tegmental Area, Nucleus Accumbens, Prefrontal Cortex, and Caudate Nucleus and Locomotor Activity Are Modulated in Dose-Response Characteristics by Methylphenidate. Brain Research, 1073-1074, 164-174. http://dx.doi.org/10.1016/j.brainres.2005.12.055

[9] Baumgaertel, A., Wolraich, M.L. and Dietrich, M. (1995) Comparison of Diagnostic Criteria for Attention Deficit Disorders in a German Elementary School Sample. Journal of the American Academy of Child \& Adolescent Psychiatry, 34, 629-638. http://dx.doi.org/10.1097/00004583-199505000-00015

[10] Bird, H.R., Canino, G., Rubio-Stipec, M., Gould, M.S., Ribera, J., Sesman, M., Woodbury, M., Huertas-Goldman, S., Pagan, A. and Sanchez-Lacay, A. (1988) Estimates of the Prevalence of Childhood Maladjustment in a Community Survey in Puerto Rico. The Use of Combined Measures. Archives of General Psychiatry, 45, 1120-1126. http://dx.doi.org/10.1001/archpsyc.1988.01800360068010

[11] Esser G., Schmidt M.H. and Woerner, W. (1990) Epidemiology and Course of Psychiatric Disorders in School-Age Children-Results of a Longitudinal Study. Journal of Child Psychology and Psychiatry, 31, 243-263. http://dx.doi.org/10.1111/j.1469-7610.1990.tb01565.x

[12] Goldman, L.S., Genel, M., Bezman, R.J. and Slanetz, P.J. (1998) Diagnosis and Treatment of Attention Deficit Hyperactivity Disorder in Children and Adolescents. Journal of the American Medical Association, 279, 1100-1107. http://dx.doi.org/10.1001/jama.279.14.1100

[13] Lee, S.H., Seo, W.S., Sung, H.M., Choi, T.Y., Kim, S.Y., Choi, S.J., Koo, B.H. and Lee, J.H. (2012) Effect of Methylphenidate on Sleep Parameters in Children with ADHD. Psychiatry Investigation, 9, 384-390. http://dx.doi.org/10.4306/pi.2012.9.4.384

[14] Froehlich, T., Lanphear, B., Epstein, J., Barbaresi, W., Katusic, S. and Kahn, R.S. (2007) Prevalence, Recognition, and Treatment of Attention-Deficit/Hyperactivity Disorder in a National Sample of US Children. Archives of Pediatrics and Adolescent Medicine, 161, 857-864. http://dx.doi.org/10.1001/archpedi.161.9.857

[15] Spencer, T.J., Biederman, J. and Mick, E. (2007) Attention-Deficit/Hyperactivity Disorder: Diagnosis, Lifespan, Comorbidities, and Neurobiology. Ambulatory Pediatrics, 7, 73-81. http://dx.doi.org/10.1016/j.ambp.2006.07.006

[16] Huttenlocher, P.R. (1979) Synaptic Density in Human Frontal Cortex: Developmental Changes and Effects of Aging. Brain Research, 163, 195-205. http://dx.doi.org/10.1016/0006-8993(79)90349-4

[17] Moll, G.H., Mehnert, C., Wicker, M., Bock, N., Rothenberger, A., Ruther, E. and Huether, G. (2000) Age-Associated Changes in the Densities of Presynaptic Monoamine Transporters in Different Regions of the Rat Brain from Early Juvenile Life to Late Adulthood. Developmental Brain Research, 119, 251-257. http://dx.doi.org/10.1016/S0165-3806(99)00182-0

[18] O’Donnell, P. (2010) Adolescent Maturation of Cortical Dopamine. Neurotoxicity Research, 18, 306-312. http://dx.doi.org/10.1007/s12640-010-9157-3

[19] Gronier, B., Aston, J., Liauzun, C. and Zetterstrom, T. (2010) Age-Dependent Effects of Methylphenidate in the Prefrontal Cortex: Evidence from Electrophysiological and Arc Gene Expression Measurements. Journal of Psychopharmacology, 24, 1819-1827. http://dx.doi.org/10.1177/0269881109359100 
[20] Tseng, K.Y. and O’Donnel, P. (2007) D2 Dopamine Receptors Recruit GABA Component for Their Attention of Excitatory Synaptic Transmission in the Adult Rat Prefrontal Cortex. Synapse G1, 10, 843-850.

[21] Volkow, N., Wang, G.L., Fowler, J., Fischman, M., Foltin, R., Abumrad, N., Gatley, S., Logan, J., Wong, C., Gifford, A., Ding, Y., Hitzemann, R. and Pappas, N. (1999) Methylphenidate and Cocaine Have Similar in Vivo Potency to Block Dopamine Transporters in the Human Brain. Life Sciences, 65, PL7-PL12. http://dx.doi.org/10.1016/s0024-3205(99)00225-8

[22] Brandon, C.L., Marinelli, M. and White, F.J. (2003) Adolescent Exposure to Methylphenidate Alters the Activity of Rat Midbrain Dopamine Neurons. Biological Psychiatry, 54, 1338-1344. http://dx.doi.org/10.1016/S0006-3223(03)00787-X

[23] Canese, R., Adriani, W., Marco, E.M., De Pasquale, F., Lorenzini, P., De Luca, N., Fabi, F., Podo, F. and Laviola, G. (2009) Peculiar Response to Methylphenidate in Adolescent Compared to Adult Rats: A phMRI Study. Psychopharmacology, 203, 143-153. http://dx.doi.org/10.1007/s00213-008-1379-1

[24] Kuczenski, R. and Segal, D.S. (2001) Locomotor Effects of Acute and Repeated Threshold Doses of Amphetamine and Methylphenidate: Relative Roles of Dopamine and Norepinephrine. The Journal of Pharmacology and Experimental Therapeutics, 296, 876-883.

[25] Levant, B., Zarcone, T.J., Davis, P.F., Ozias, M.K. and Fowler, S.C. (2001) Differences in Methylphenidate Dose Response between Periadolescent and Adult Rats in the Familiar Arena-Novel Alcove Task. The Journal of Pharmacology and Experimental Therapeutics, 337, 83-91. http://dx.doi.org/10.1124/jpet.110.174425

[26] Roessner, V., Sagvolden, T., Dasbanerjee, T., Middleton, F.A., Faraone, S.V., Walaas, S.I., Becker, A., Rothenberger, A. and Bock, N. (2010) Methylphenidate Normalizes Elevated Dopamine Transporter Densities in an Animal Model of the Attention-Deficit/Hyperactivity Disorder Combined Type, but Not to the Same Extent in One of the AttentionDeficit/Hyperactivity Disorder Inattentive Type. Neuroscience, 167, 1183-1191. http://dx.doi.org/10.1016/j.neuroscience.2010.02.073

[27] Walker, D.Q., Morris, S.E., Arrant, A.E., Nagel, J.M., Parylak, S., Zhou, G., Caster, J.M. and Kuhn, C.M. (2010) Dopamine Uptake Inhibitors but Not Dopamine Releasers Induce Greater Increases in Motor Behavior and Extracellular Dopamine in Adolescent Rats than in Adult Male Rats. The Journal of Pharmacology and Experimental Therapeutics, 335, 124-132. http://dx.doi.org/10.1124/jpet.110.167320

[28] Jones, Z. and Dafny, N. (2013) Dose Response Effect of Methylphenidate on Ventral Tegmental Area Neurons and Animal Behavior. Brain Research Bulletin, 96, 86-92. http://dx.doi.org/10.1016/j.brainresbull.2013.03.004

[29] Tang, B. and Dafny, N. (2012) Methylphenidate Modulates the Locus Ceruleus Neuronal Activity in Freely Behaving Rat. European Journal of Pharmacology, 695, 48-56. http://dx.doi.org/10.1016/j.ejphar.2012.08.016

[30] Tang, B. and Dafny, N. (2013) Dorsal Raphe Neuronal Activities Are Modulated by Methylphenidate. Journal of Neural Transmission, 120, 721-731. http://dx.doi.org/10.1007/s00702-012-0917-5

[31] Tang, B. and Dafny, N. (2013) Behavioral and Dorsal Raphe Neuronal Activity Following Acute and Chronic Methylphenidate in Freely Behaving Rats. Brain Research Bulletin, 98, 53-63. http://dx.doi.org/10.1016/j.brainresbull.2013.06.004

[32] Bolanos, C.A., Glatt, S.J. and Jackson, D. (1998) Subsensitivity to Dopaminergic Drugs in Periadolescent Rats: A Behavioral and Neurochemical Analysis. Developmental Brain Research, 111, 25-33. http://dx.doi.org/10.1016/S0165-3806(98)00116-3

[33] Brandon, C.L., Marinelli, M., Baker, L.K. and White, F.J. (2001) Enhanced Reactivity and Vulnerability to Cocaine Following Methylphenidate Treatment in Adolescent Rats. Neuropsychopharmacology, 25, 651-661. http://dx.doi.org/10.1016/S0893-133X(01)00281-0

[34] Dafny, N. and Yang, P.B. (2006) The Role of Age, Genotype, Sex, and Route of Acute and Chronic Administration of Methylphenidate: A Review of Its Locomotor Effects. Brain Research Bulletin, 68, 393-405. http://dx.doi.org/10.1016/j.brainresbull.2005.10.005

[35] Laviola, G., Wood, R.D., Kuhn, C., Francis, R. and Spear, L.P. (1995) Cocaine Sensitization in Periadolescent and Adult Rats. The Journal of Pharmacology and Experimental Therapeutics, 275, 345-357.

[36] Rezvani, A.H. and Levin, E.D. (2004) Adolescent and Adult Rats Respond Differently to Nicotine and Alcohol: Motor Activity and Body Temperature. International Journal of Developmental Neuroscience, 22, 349-354. http://dx.doi.org/10.1016/j.ijdevneu.2004.03.007

[37] Sherwood, N. and Timiras, P. (1970) A Stereotaxic Atlas of the Developing Rat Brain. University of California Press, Oakland.

[38] Chong, S.L., Claussen, C.M. and Dafny, N. (2012) Nucleus Accumbens Neuronal Activity in Freely Behaving Rats Is Modulated Following Acute and Chronic Methylphenidate Administration. Brain Research Bulletin, 87, 445-456. http://dx.doi.org/10.1016/j.brainresbull.2012.01.004 
[39] Claussen, C. and Dafny, N. (2012) Acute and Chronic Methylphenidate Modulates the Neuronal Activity of the Caudate Nucleus Recorded from Freely Behaving Rats. Brain Research Bulletin, 87, 387-396. http://dx.doi.org/10.1016/j.brainresbull.2011.10.008

[40] Dafny, N. (1980) Neurophysiological Evidence for Tolerance and Dependence on Opiates: Simultaneous Multiunit Recordings from Septum, Thalamus, and Caudate Nucleus. Journal of Neuroscience Research, 5, 339-349. http://dx.doi.org/10.1002/jnr.490050410

[41] Salek, R.L., Claussen, C.M., Perez, A. and Dafny, N. (2012) Acute and Chronic Methylphenidate Alters Prefrontal Cortex Neuronal Activity Recorded from Freely Behaving Rats. European Journal of Pharmacology, 679, 60-67. http://dx.doi.org/10.1016/j.ejphar.2012.01.009

[42] Yang, P., Swann, A. and Dafny, N. (2007) Chronic Administration of Methylphenidate Produces Neurophysiological and Behavioral Sensitization. Brain Research, 1145, 66-80. http://dx.doi.org/10.1016/j.brainres.2007.01.108

[43] Chelaru, M.I., Yang, P.B. and Dafny, N. (2012) Sex Differences in the Behavioral Response to Methylphenidate in Three Adolescent Rat Strains (WKY, SHR, SD). Behavioural Brain Research, 226, 8-17. http://dx.doi.org/10.1016/j.bbr.2011.08.027

[44] Drouin, C., Page, M. and Waterhouse, B. (2006) Methylphenidate Enhances Noradrenergic Transmission and Suppresses Mid- and Long-Latency Sensory Responses in the Primary Somatosensory Cortex of Awake Rats. Journal of Neurophysiology, 96, 622-632. http://dx.doi.org/10.1152/jn.01310.2005

[45] Gaytan, O., Ghelani, D., Martin, S., Swann, A. and Dafny, N. (1996) Dose Response Characteristics of Methylphenidate on Different Indicies of Rats' Locomotor Activity at the Beginning of the Dark Cycle. Brain Research, 727, 13-21. http://dx.doi.org/10.1016/0006-8993(96)00296-X

[46] Gaytan, O., Al-Rahim, S., Swann, A. and Dafny, N. (1997) Sensitization to Locomotor Effects of Methylphenidate in the Rat. Life Sciences, 61, PL101-PL107. http://dx.doi.org/10.1016/s0024-3205(97)00598-5

[47] Gaytan, O., Yang, P., Swann, A. and Dafny, N. (2000) Diurnal Differences in Sensitization to Methylphenidate. Brain Research, 864, 24-39. http://dx.doi.org/10.1016/S0006-8993(00)02117-X

[48] Yang, P., Swann, A. and Dafny, N. (2003) Chronic Pretreatment with Methylphenidate Induces Cross-Sensitization with Amphetamine. Life Sciences, 73, 2899-2911. http://dx.doi.org/10.1016/S0024-3205(03)00673-8

[49] Yang, P.B., Atkins, K.D. and Dafny, N. (2011) Behavioral Sensitization and Cross-Sensitization between Methylphenidate, Amphetamine, and 3,4-Methylenedioxymethamphetamine (MDMA) in Female SD Rats. European Journal of Pharmacology, 66, 72-85. http://dx.doi.org/10.1016/j.ejphar.2011.04.035

[50] Yang, P.B., Cuellar III, D.O., Swann, A.C. and Dafny, N. (2011) Age and Genetic Strain Differences in Response to Chronic Methylphenidate Administration. Behavioural Brain Research, 218, 206-217. http://dx.doi.org/10.1016/j.bbr.2010.11.034

[51] Claussen, C.M., Chong, S.L. and Dafny, N. (2014) Nucleus Accumbens Neuronal Activity Correlates to the Animals Behavioral Response to Acute and Chronic Methylphenidate. Physiology \& Behavior, 129, 85-94. http://dx.doi.org/10.1016/j.physbeh.2014.02.024

[52] Yang, P., Swann, A. and Dafny, N. (2006) Chronic Methylphenidate Modulates Locomotor Activity and Sensory Evoked Responses in the VTA and NAc of Freely Behaving Rats. Neuropharmacology, 51, 546-556. http://dx.doi.org/10.1016/j.neuropharm.2006.04.014

[53] Kraut, A.A., Langner, I., Lindemann, C., Banaschewski, T., Petermann, U., Petermann, F., Mikolajczyk, R.T. and Garbe, E. (2013) Comorbidities in ADHD Children Treated with Methylphenidate: A Database Study. BMC Psychiatry, 13, 11. http://dx.doi.org/10.1186/1471-244X-13-11

[54] Wilens, T.E., Adler, L.A., Adams, J., Sgambati, S., Rotrosen, J., Sawtelle, R., Utzinger, L. and Fusillo, S. (2008) Misuse and Diversion of Stimulants Prescribed for ADHD: A Systematic Review of the Literature. Journal of the American Academy of Child \& Adolescent Psychiatry, 47, 21-31. http://dx.doi.org/10.1097/chi.0b013e31815a56f1

[55] Kim, Y., Teylan, M.A., Baron, M., Sands, A., Nairn, A.C. and Greengard, P. (2009) Methylphenidate-Induced Dendritic Spine Formation and DeltaFosB Expression in Nucleus Accumbens. Proceedings of the National Academy of Sciences of the United States of America, 106, 2915-2920. http://dx.doi.org/10.1073/pnas.0813179106

[56] Russo, S.J., Dietz, D.M., Dumitriu, D., Morrison, J.H., Malenka, R.C. and Nestler, E.J. (2010) The Addicted Synapse: Mechanisms of Synaptic and Structural Plasticity in Nucleus Accumbens. Trends in Neurosciences, 33, 267-276. http://dx.doi.org/10.1016/j.tins.2010.02.002

[57] Gronier, B. (2011) In Vivo Electrophysiological Effects of Methylphenidate in the Prefrontal Cortex; Involvement of D1 and Alpha 2 Adrenergic Receptors. European Neuropsychopharmacology, 212, 192-204. http://dx.doi.org/10.1016/j.euroneuro.2010.11.002

[58] Steketee, J.D. (2003) Neurotransmitter Systems of the Medial Prefrontal Cortex: Potential Role in Sensitization to 
Psychostimulants. Brain Research Reviews, 41, 203-228. http://dx.doi.org/10.1016/S0165-0173(02)00233-3

[59] Alburges, M.E., Hoomakker, A.J., Horner, K.A., Fleckenstein, A.E. and Hanson, G.R. (2011) Methylphenidate Alters Basal Ganglia Neurotensin Systems through Dopaminergic Mechanisms: A Comparison with Cocaine Treatment. Journal of Neurochemistry, 117, 470-478. http://dx.doi.org/10.1111/j.1471-4159.2011.07215.x

[60] Arnsten, A.F. and Li, B.M. (2005) Neurobiology of Executive Functions: Catecholamine Influences on Prefrontal Cortical Functions. Biological Psychiatry, 57, 1377-1384. http://dx.doi.org/10.1016/j.biopsych.2004.08.019

[61] Arnsten, A.F. and Dudley, A.G. (2005) Methylphenidate Improves Prefrontal Cortical Cognitive Function through Alpha2 Adrenoceptor and Dopamine D1 Receptor Actions: Relevance to Therapeuric Effects in Attention Deficitt Hyperactivity Disorder. Behavioral and Brain Functions, 1, 2.

[62] Chen, J.C., Chen, P.C. and Chiang, Y.C. (2009) Molecular Mechanisms of Psychostimulant Addiction. Chang Gung Medical Journal, 32, 148-154.

[63] Voltz, T.J. (2008) Neuropharmacological Mechanisms Underlying the Neuroprotective Effects of Methylphenidate. Current Neuropharmacology, 6, 379-385. http://dx.doi.org/10.2174/157015908787386041

[64] Del Arco, A. and Mora, F. (2009) Neurotransmitters and Prefrontal Cortex-Limbic System Interactions: Implications for Plasticity and Psychiatric Disorders. Journal of Neural Transmission, 116, 941-952. http://dx.doi.org/10.1007/s00702-009-0243-8

[65] Chao, J. and Nestler, E.J. (2004) Molecular Neurobiology of Drug Addiction. Annual Review of Medicine, 55, 113-132. http://dx.doi.org/10.1146/annurev.med.55.091902.103730

[66] Nestler, E.J. (2004) Molecular Mechanisms of Drug Addiction. Neuropharmacology, 47, 24-32. http://dx.doi.org/10.1016/j.neuropharm.2004.06.031

[67] Gatley, S.J., Volkow, N.D., Gifford, A.N., Fowler, J.S., Dewey, S.L., Ding, S.L., Ding, Y.S. and Logann, I. (1999) Dopamine-Transporter Occupancy after Intravenous Doses of Cocaine and Methylphenidate in Mice and Humans. Psychopharmacology, 146, 93-100. http://dx.doi.org/10.1007/s002130051093

[68] Volkow, N.D., Fowler, J.S., Wang, G., Ding, Y. and Gatley, S.J. (2002) Mechanism of Action of Methylphenidate: Insights from PET Imaging Studies. Journal of Attention Disorders, 6, 31-43.

[69] Nicola, S.M., Kombian, S.B. and Malenka, R.C. (1996) Pyschostimulant Depress Excitatory Synaptic Transmission in the Nucleus Accumbens via Presynaptic D1 Like Dopamine Receptors. The Journal of Neuroscience, 16, 1591-1604.

[70] Dietz, D.M., Dietz, K.C., Nestler, E.J. and Russo, S.J. (2009) Molecular Mechanisms of Psychostimulant-Induced Structural Plasticity. Phamacopsychiatry, 42, 69-78. http://dx.doi.org/10.1055/s-0029-1202847

[71] Robinson, T.E. and Kolb, B. (1997) Persistent Structural Modifications in Nucleus Accumbens and Prefrontal Cortex Neurons Produced by Previous Experience with Amphetamine. The Journal of Neuroscience, 17, 8491-8497.

[72] Robinson, T.E. and Kolb, B. (1999) Alterations in the Morphology of Dendrites and Dendritic Spines in the Nucleus Accumbens and Prefrontal Cortex Following Repeated Treatment with Amphetamine or Cocaine. European Journal of Neuroscience, 11, 1598-1604. http://dx.doi.org/10.1046/j.1460-9568.1999.00576.x

[73] Sun, W., Zhou, L., Hazim, R., Quinones-Jenab, V. and Jenab, S. (2007) Effects of Acute Cocaine on ERK and DARPP-32 Phosphorylation Pathways in the Caudate-Putamen of Fischer Rats. Brain Research, 1178, 12-19. http://dx.doi.org/10.1016/j.brainres.2007.07.051

[74] Devilbliss, D.M. and Berridge, C.W. (2008) Cognition-Enhancing Dose of Methylphenidate Preferentially Increases Prefrontal Cortical Neuronal Responsiveness. Biological Psychiatry, 65, 626-635. http://dx.doi.org/10.1016/j.biopsych.2008.04.037

[75] Urban, K.B., Waterhouse, B.D. and Gao, W.J. (2012) Distinct Age Dependent Affects of Methylphenidate on Developing and Adult Prefrontal Neurons. Biological Psychiatry, 72, 880-888. http://dx.doi.org/10.1016/j.biopsych.2012.04.018 